JELENA D. RUSMIROVIĆ ${ }^{*}$, ALEKSANDRA R. BOŽIĆ ${ }^{2}$ MARINA STAMENOVIĆ ${ }^{2}$, PAVLE SPASOJEVIĆ ${ }^{1}$, MILICA RANČIĆ ${ }^{3}$, IVANA STOJILJKOVIĆ ${ }^{3}$, ALEKSANDARD. MARINKOVIĆ ${ }^{4}$

${ }^{1}$ University of Belgrade, Innovation center, Faculty of Technology and Metallurgy, Belgrade, Serbia, ${ }^{2}$ University of Belgrade, Belgrade Polytechnic, Belgrade, Serbia, ${ }^{3}$ University of Belgrade, Faculty of Forestry, Belgrade, Serbia, ${ }^{4}$ University of Belgrade, Faculty of Technology and Metallurgy, Belgrade, Serbia
Scientific paper

ISSN 0351-9465, E-ISSN 2466-2585

UDC:620.197.6(n)

doi:10.5937/ZasMat1601047R

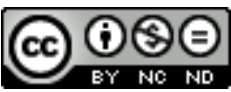

Zastita Materijala 57 (1)

$47-54(2016)$

\title{
Alkyd nanocomposite coatings based on waste pet glicolyzates and modified silica nanoparticles
}

\begin{abstract}
Synthesis of high-performance alkyd resins (ARs) based on waste poly(ethylene terephthalate) (PET) glycolyzates is presented. PET glycolyzates were synthesized by catalytic depolymerization with trimethylolpropane (TMP) and trimethylolethane (TME) and used as replacement of polyhydroxylic component during the ARs synthesis. The obtained glycolyzates and produced ARs were analyzed using FTIR, ${ }^{1} \mathrm{H}$ and ${ }^{13} \mathrm{C}$ NMR spectroscopy and acid, iodine, and hydroxyl value were determined. Rheological properties of the synthesized ARs, as well as, thickness, adhesion, hardness and the gloss values were determined. All synthesized ARs show good adhesion and hardness and the gloss values are greater than $95 \%$. The influence of the addition of vinyl modified nanosilica Aerosil ${ }^{\Theta}$ R380, functionalized with 3-(trimethoxysilyl)propyl methacrylate (TMSPM) and tris(2-methoxyethoxy)(vinyl)silane (TMEVS), on the mechanical and anticorrosive characteristics of the prepared nanocomposite coatings, based on ARs, was investigated.
\end{abstract}

Keywords: Alkyd resins, waste PET glycolyzates, nanosilica, nanocomposite coatings.

\section{INTRODUCTION}

As one of the most used synthetic polymer, especially for food, water and soft drink packaging, poly(ethylene terephthalate) (PET) causes serious environmental problems because of large amount of disposal arising from aggravated decomposition of PET [1, 2]. Waste PET recycling, as one of the most successful polymers recycling method prevents pollution of environment and saves energy. There are different methods for recycling of waste PET: primary (re-extrusion), secondary (mechanical), tertiary (chemical) and quaternary (energy recovery) recycling and chemical recycling transforms waste PET into monomers and oligomers such as terephthalic acid (TPA) or bis(2hydroxyethyl) terephthalate (BHET) which can be reused for new products manufacturing [3, 4]. Oligomeric products obtained by waste PET chemical recycling are used for the synthesis of an alkyd resins, polyester resins, epoxy resins and polyurethane resins $[4,5]$.

\footnotetext{
${ }^{*}$ Corresponding author: Jelena Rusmirović

E-mail: jrusmirovic@tmf.bg.ac.rs

Paper received: 15.10.2015.

Paper accepted: 09.12.2015

Paper is available on the website: www.idk.org.rs/casopis
}

Due to very good performances and great compatibility with many polymers, the production of alkyd resins (ARs) records growth comparing to other synthetic-based polymer resins $[6,7]$. The fact that the raw renewable materials can be used in the ARs synthesis makes ARs very attractive, both from the environmental and the economical point of view [8]. The post-consumer PET can be used in the alkyd resin synthesis, replacing a fraction of the phthalic anhydride (PA) and ethylene glycol (EG) from conventional synthesis, and thus, replacing them or obtaining them from the recycling of other materials [5].

Incorporation of inorganic nanoparticles in polymer matrices, new reinforced composite materials with unique features were obtained [9]. According to the strong interactions between silica nanoparticles and strong filler cross-linking [10], a significant improvement of physical-mechanical, as well as, thermal properties of polymer nanocomposite materials were obtained by the addition of silica into polymer [11-13]. Good filler dispersion, stability and compatibility, as well as, chemical reactivity with the polymer matrix can be obtained by chemical modification of hydroxyl groups on the silica surface with organosilanes [14, 15]. 
In this work, mechanical properties of hybrid composite materials, prepared using ARs based on recycled PET and chemically modified silica nanoparticles, were investigated. ARs were synthesized from a tetra-hydroxy functional product, obtained by catalytic glycolysis of waste PET with trimethylolpropane (TMP) and trimethylolethane (TME), and pentaerythritol (PE), phthalic anhydride (PA) and fatty acid of linseed oil. Furthermore, nanocomposites based on the obtained ARs and fumed vinyl modified nanosilica Aerosil ${ }^{\circledR}$ R380 were prepared in order to study the influence of the type of silica modification and content of incorporated nanoparticles on mechanical properties of the obtained nanocomposites.

\section{EXPERIMENTAL PART}

\subsection{Materials}

PET was collected from waste bottle packaging material. It was flaked into small pieces and washed with a detergent, ethanol and dichloromethane. Trimethylolpropane (TMP), trimethylolethane (TME), pentaerythritol (PE), phthalic anhydride (PA), tetrabutyltitanate (TBT), potassium hydroxide and xylene ( $X Y L$ ) were obtained from Sigma-Aldrich, and used without any further purification. Dichloromethane (DCM), 3(trimethoxysilyl)propyl methacrylate (TMSPM) and tris(2-methoxyethoxy)(vinyl)silane (TMEVS) were purchased from Fluka. Fumed silica, with trade name $A E R O S I{ }^{\circledR} 380$, was kindly provided by Evonik (Evonik industries, Essen, Germany). AEROSIL ${ }^{\circledR} 380$ is hydrophilic fumed silica with a specific surface area of $380 \mathrm{~m}^{2} / \mathrm{g} .5 \%$ solution of calcium octoate $(\mathrm{Ca})$ and cobalt octoate (Co), as well as $8 \%$ solution of zirconium octoate $(\mathrm{Zr})$ dissolved in white spirit was used as purchased.

\subsection{Glycolysis of PET}

Glycolysis of PET using TMP and TME was performed according to the procedure described in literature earlier $[6,16]$. Molar ratio of PET and multifunctional alcohol was 1:3 and TBT was used as catalyst. The products of PET glycolysis were designated as G-TMP and G-TME.

\subsection{Isolation of fatty acid of linseed oil (FLA)}

In a four-necked flask of $500 \mathrm{ml}$, equipped with a reflux condenser, mechanical stirrer, thermometer and dropping funnel, the potassium hydroxide solution in ethanol was slowly added dropwise into ethanol solution of linseed oil (LO) (molar ratio of potassium hydroxide/linseed oil was 3.5/1). After the reaction mixture was maintained at temperature below $10{ }^{\circ} \mathrm{C}$ for 1 hour, the temperature was raised to $50{ }^{\circ} \mathrm{C}$ and held for 2 hours and then the residual solvent were removed by distillation. The resulting pasty residue was dissolved in the required amount of distilled water to get clear solution which was acidified by addition of appropriate volume of $10 \% \mathrm{HCl}$ until $\mathrm{pH}$ of 3 was attained. The top layer of linseed oil fatty acids (LFA) was separated and refined twice with $250 \mathrm{ml}$ of diethyl ether and vacuum distillated which enabled drying and removal of low boiling component of reaction product. Characteristics of LFA: AV=210 mg KOH/g; JV=157 g/100 g [16].

\subsection{Synthesis of alkyd resins}

a) Synthesis of AR1 resin - After the glycolysis using TMP, the reaction mixture with G-TMP glycolysis product was cooled to $90 \stackrel{\circ}{\circ} \mathrm{C}$ and $47.0 \mathrm{~g}$ of LFA, $20.5 \mathrm{~g}$ of PA and 12.0 of PER were added. For the ARs synthesis, a four-necked reactor equipped with a stirrer, thermometer, nitrogen inlet tube and Dean-Stark separator was used. XYL was used as the azeotropic solvent. All ingredients were charged into the reactor and the reaction mixture was heated to $220^{\circ} \mathrm{C}$. The acid value of the reaction mixture was measured by taking sample aliquots at various time intervals. The reaction was quenched by allowing it to cool when the acid value was about $10 \mathrm{mg} \mathrm{KOH} / \mathrm{g}$. The alkyd resins were diluted to $60 \%$ of solid content by adding appropriate amount of xylene.

b) Synthesis of AR2 resin - AR2 was synthesized according to the procedure 2.4.a) from the G-TME glycolysis product with the following modification: $48.5 \mathrm{~g}$ of LFA, $21.5 \mathrm{~g}$ of PA and 15.0 $g$ of PER.

\subsection{Chemical modification of silica nanoparticles (AEROSIL ${ }^{\circledR} 380$ )}

In order to study influence of silica modification on mechanical properties of the ARs based nanocomposites and silica dispersion in polymer matrix, two types of silane coupling agents containing vinyl and mathacryloxy were used for silica nanoparticles functionalization. The mechanism of AEROSIL ${ }^{\circledR} 380$ modifications by covalent bonding with TMSPM and TMEVS is shown on Figure 1.

Procedure: In a dry three-necked glass reactor, equipped with a magnetic stirrer, reflux condenser, thermometer and a nitrogen inlet tube, $1.0 \mathrm{~g}$ of silica (AEROSIL ${ }^{\circledR} 380$ ) and $120 \mathrm{ml}$ of dry toluene were charged. After dispersion of silica nanoparticles in toluene under ultrasound for $5 \mathrm{~min}$, $3.97 \mathrm{~g}$ of silane coupling agent was added and the modification reaction was continued for 48 hours at $25^{\circ} \mathrm{C}$ under the nitrogen atmosphere. Ultrasonic bath (Bandelin electronic, Berlin, Germany, power $120 \mathrm{~W}$, frequency $35 \mathrm{kHz}$ ) was thermostated by circulating water through the jacket, and used for silane modification as well as for preparation of nanocomposite coating. The modified silica was separated from solution by vacuum filtration, and 
the product was washed twice with the toluene, and then dispersed in $120 \mathrm{ml}$ of toluene using ultrasound bath. In the case of TMSPM modifi- cation, the product was designated as $\mathrm{SiO}_{2} \mathrm{MA}$, and in the case of TMEVS as $\mathrm{SiO}_{2} \mathrm{VY}$.

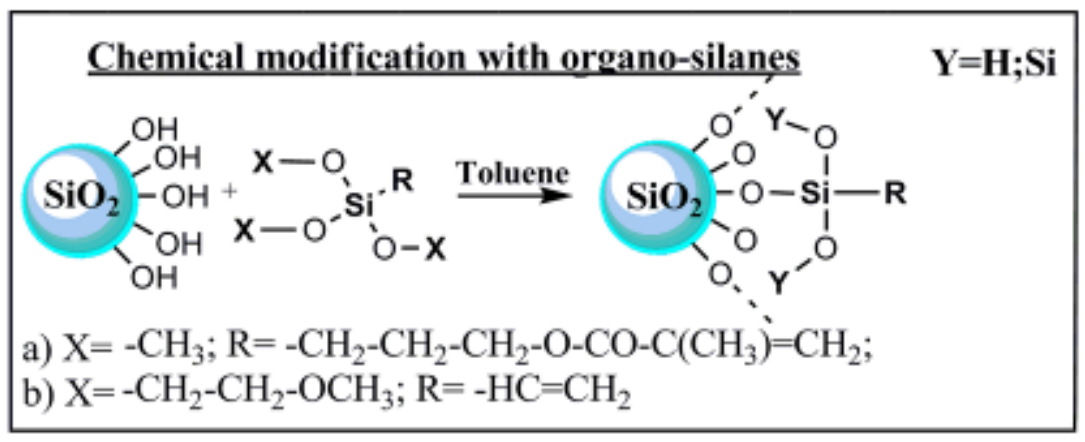

Figure 1 - Chemical modification of $A E R O S I L^{\circledR} 380$ with a) TMSPM and b) TMEVS

\subsection{Production of nanocomposite coatings}

Initially, modified silica nanoparticles were dispersed in white spirit and after that, in alkyd resin with the nanofiller percent in the range of 0.1 $-1.0 \mathrm{wt} \%$. A mixture of $5 \mathrm{wt} \% \mathrm{Ca}$ and $\mathrm{Co}$, and 8 $\mathrm{wt} \%$ of $\mathrm{Zr}$ was added in the proportion of $1 \mathrm{wt} \%$ as the best drying catalyst system. The homogenization of fumed silica with ARS was achieved by using ultrasound (2 minn) and modified laboratory homogenizer (15 min/600 $\% / \mathrm{min}$ ). The ARs and modified silica based coatings were applied by a wire-wound applicator (wet thickness of $100 \mu \mathrm{m}$ ) on mild steel $15 \mathrm{~cm} \times 10 \mathrm{~cm}$ plates for evaluating flexibility, gloss and adhesion and $10 \mathrm{~cm} \times 10 \mathrm{~cm}$ glass plates for evaluating hardness, thickness and adhesion properties.

\subsection{Characterization methods}

The hydroxyl (HV) and the acid values (AV) of the synthesized alkyd resins were determined by standard methods [17, 18]. lodine value was determined by the Wijs method. Structural analysis of modified silica nanofiller and synthesized ARs were done using Fourier-transform infrared (FTIR) spectra (FTIR BOMEM MB 100 instrument). The ${ }^{1} \mathrm{H}$ and ${ }^{13} \mathrm{C}$ NMR spectral measurements of the alkyd resins were performed on a Varian Gemini 2000 $(200 \mathrm{MHz})$. The spectra were recorded at room temperature in deuterated chloroform $\left(\mathrm{CDCl}_{3}\right)$. Rheological analysis of ARs was obtained using dynamic-mechanical analysis, which was performed on a Discovery Hybrid Rheometer HR2 (TA Instruments).

The flexibility of dry alkyd film was measured according to the ISO 1520 [19] using a cupping tester (Byk PF-5400, BYK-Gardner GmbH, Geretsried, Germany). The adhesion of the films to the substrate was characterized using the crosshatch adhesion method (ASTM D 3359 [20]), which is a simple and effective method for evaluating adhesion. Gloss was measured by a single angle gloss meter (AG-4442, BYK-Gardner $\mathrm{GmbH}$, Geretsried, Germany). All measurements were done at an angle of $60^{\circ}$ (ASTM D 523 [21]). Hardness was measured by a pendulum hardness tester (Byk PH-5858, BYK-Gardner GmbH, Geretsried, Germany) using a König pendulum according to ASTM D 4366 [22].

Thickness, adhesion, swelling, corrosion, spraying and layering properties of the alkyd anticorrosion coating films were measured according to SRPS EN ISO 4628 [23] standard.

\section{RESULTS AND DISCUSSION}

\subsection{Glycolysis of PET}

The trans-esterification reactions of PET waste glycolysis was performed by using TMP and TME in the presence of TBT catalysts. The $H V$ and $A V$ values and the data obtained from elemental analysis of the glycolyzed products are presented in Table 1.

Table 1 - The HV and AV values and the results of elemental analysis of the products of PET glycolysis

\begin{tabular}{|c|c|c|c|c|c|c|c|}
\hline Glycolyzate & $\begin{array}{c}\mathrm{HV}_{\text {theor, }} \\
m g ~ K O H / g\end{array}$ & $\begin{array}{c}\mathrm{HV}_{\text {exp }}, \\
m g ~ K O H / g\end{array}$ & $\begin{array}{c}\mathrm{AV} \text { exp, } \\
m g ~ K O H / g\end{array}$ & & $\% \mathrm{C}$ & $\% \mathrm{H}$ & $\% \mathrm{O}^{*}$ \\
\hline G-TMP & 563 & 551 & 6.5 & Exp. & 59.45 & 8.09 & 32.46 \\
\cline { 5 - 8 } & & & & Calc. & 60.29 & 7.59 & 32.12 \\
\hline G-TME & 608 & 610 & \multirow{2}{*}{4.3} & Exp. & 59.20 & 6.51 & 34.29 \\
\cline { 5 - 8 } & & & & Calc. & 58.37 & 7.07 & 34.56 \\
\hline
\end{tabular}

*The oxygen percent was calculated as the difference to $100 \%$. 
The hydroxyl-terminated glycolysis products present formation of the corresponding ester of terephthalic acid and multifunctional alcohol which is confirmed by comparing the hydroxyl values and results of elemental analysis of the obtained glycolyzates with those obtained according to the theoretical calculation for purified products.

\subsection{FTIR and NMR analysis of $A E R O S I L{ }^{\circledR} 380$, glycolysis product and ARs}

The products obtained by chemical modification of silica AEROSIL ${ }^{\circledR} 380$, PET glycolysis and ARs were further characterized by FTIR and NMR spectroscopy. FTIR spectra of the unmodified and modified silica nanoparticles with TMSPM and TMEVS (method 2.5.) are shown on Figure 2.

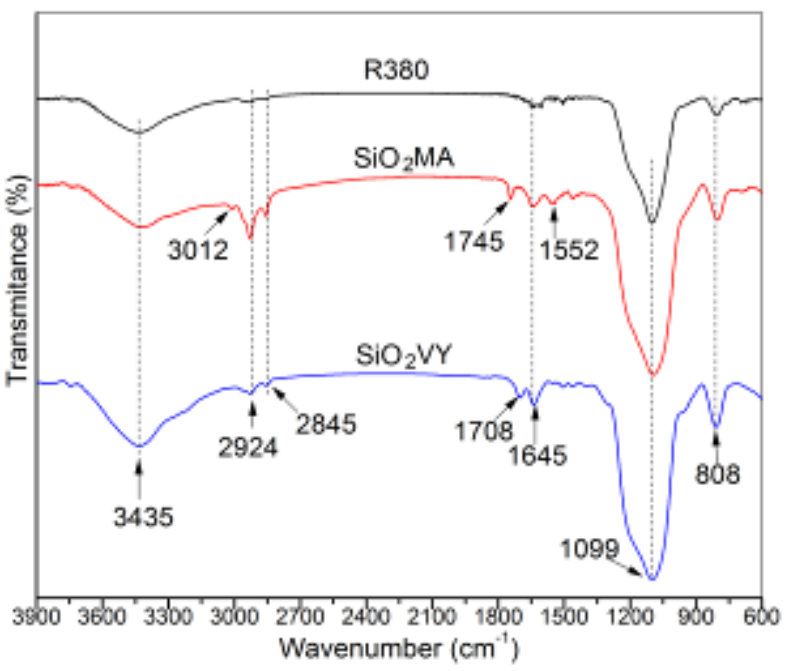

Figure 2 - FTIR spectra of the unmodified, $\mathrm{SiO}_{2} \mathrm{MA}$, and $\mathrm{SiO}_{2} \mathrm{VY}$ nanoparticles (method 2.5.)

Characteristic absorption peak for modified and unmodified silica nanoparticles appears at 1099 $\mathrm{cm}^{-1}$ and represents the stretching vibration of $\mathrm{Si}$ $\mathrm{O}-\mathrm{Si}$ bonds (Figure 2). The $\mathrm{OH}$ stretching vibrations are observed at about $3435 \mathrm{~cm}^{-1}$ and 1645 and $808 \mathrm{~cm}^{-1}$. In the FTIR spectra of different modified silica nanoparticles (method 2.5.), the absorption peaks around 3012, 2924 and $2845 \mathrm{~cm}$ ${ }_{1}$ originate from $\mathrm{CH}_{3}$ and $\mathrm{CH}_{2}$ stretching vibrations, and peaks about $1552 \mathrm{~cm}^{-1}$ from their bending vibrations, respectively. The bands at 1745 and $1708 \mathrm{~cm}^{-1}$ are due to the $\mathrm{C}=\mathrm{O}$ functional groups present in modified silica nanoparticles. The broad band, in the spectrum of the glycolyzed products, observed between $3472 \mathrm{~cm}^{-1}$ and $3387 \mathrm{~cm}^{-1}$ was attributed to the $\mathrm{OH}$ group stretching vibration. The stretching vibrations, asymmetric and symmetric, of the methyl and methylene groups, appeared in the region $2931-2875 \mathrm{~cm}^{-1}$. The band at $1722 \mathrm{~cm}^{-1}$ was assigned to the stretching vibration of the ester carbonyl group. The main absorption bands between 1273 and $1047 \mathrm{~cm}^{-1}$ originated from the stretching vibrations of the $\mathrm{C}-\mathrm{O}$ group.
Results of the ${ }^{1} \mathrm{H}$ and ${ }^{13} \mathrm{C}$ NMR analysis of the G-TMP (exp. 2.4) are:

${ }^{1} \mathrm{H}$ NMR: $0.87\left(m, 6 \mathrm{H}, 2 \times \mathrm{CH}_{3}\right) ; 3.61(m, 8 \mathrm{H}$, $\left.4 \times \mathrm{CH}_{2} \mathrm{OH}\right) ; 3.73\left(m, 4 \mathrm{H}, 4 \times \mathrm{CH}_{2} \mathrm{OH}\right) ; 4.28-4.51$ $\left(m, 8 \mathrm{H}, 4 \times \mathrm{COOCH}_{2}\right.$, EG moiety); $7.20\left(m, 2 \mathrm{H}, \mathrm{H}_{\mathrm{Ph}}\right)$; 7.85 - $8.09\left(m, 6 \mathrm{H}, \mathrm{H}_{\mathrm{Ph}}\right)$.

${ }^{13} \mathrm{C}$ NMR: $7.50\left(2 \times \underline{\mathrm{CH}}_{3}\right), 22.74\left(\mathrm{CH}_{3} \underline{\mathrm{CH}}_{2}\right) ; 43.02$ $\left(\mathrm{C}\left(\mathrm{CH}_{2} \mathrm{CH}_{3}\right)\left(\mathrm{CH}_{2} \mathrm{OH}\right)_{2}\left(\mathrm{CH}_{2}\right)\right) ; \quad 65.16 \quad\left(\mathrm{COO} \underline{\mathrm{CH}} \mathrm{H}_{2}\right.$, TME moiety); 76.38-77.65 ( $\mathrm{COO}^{-} \mathrm{H}_{2}$, EG moiety); $129.78\left(4 \times \mathrm{C}_{\mathrm{Ph}}\right) ; 133.79(2 \times \mathrm{Ph}(\underline{\underline{C}}) \mathrm{COO}) ; 165.83$ $(2 \times \underline{\mathrm{COO}})$.

Results of the ${ }^{1} \mathrm{H}$ NMR analysis of the synthesized alkyd resins:

AR1: ${ }^{1} \mathrm{H}$ NMR $\left(200 \mathrm{MHz}, \mathrm{CDCl}_{3}\right): \delta=0.75-1.06(\mathrm{~m}$, $9 \mathrm{H}, \mathrm{CH} 3) ; 1.18-1.42\left(\mathrm{~s}, 23 \mathrm{H}, \mathrm{CH}_{2}\right) ; 1.47-1.77$ (s, $\left.5 \mathrm{H}, \mathrm{CH}_{2}\right) ; 1.88-2.16\left(\mathrm{~m}, 6 \mathrm{H},=\mathrm{CHCH}_{2}\right) ; 2.21-2.39$ $\left(\mathrm{m}, \quad 4 \mathrm{H}, \quad \mathrm{CH}_{2} \mathrm{COOCH}_{2}\right) ; 2.62-2.86(\mathrm{~m}, \quad 4 \mathrm{H}$, $\left.=\mathrm{CHCH}_{2} \mathrm{CH}=\right) ; 3.42-3.74(\mathrm{~m}, 2 \mathrm{H}, \mathrm{PACOOCH}$ and alkyl $\left.\mathrm{COOCH}_{2}\right) ; 4.03-4.74(\mathrm{~m}, 9 \mathrm{H} \text {, TPACOOCH})_{2}$; 5.24-5.49 (d, 7H, $-\mathrm{CH}=\mathrm{CH}-) ; 6.90-7.82(\mathrm{~d}, 4 \mathrm{H}$, PAH); 7.92-8.08 (d, 1H, TPAH) ppm;

Due to the similarity of the corresponding ${ }^{1} \mathrm{H}$ and ${ }^{13} \mathrm{C}$ NMR spectra of other products, G-TME (exp. 2.4) to G-TMP, as well as AR2 alkyd resin to AR1, the results are not presented.

The results of acid, hydroxyl and iodine value determination, as well as color of the synthesized alkyd resins are presented in Table 2.

Table 2 - Acid value, hydroxyl value, iodine value and color of the synthesized alkyds

\begin{tabular}{|c|c|c|c|c|}
\hline $\begin{array}{c}\text { Alkyd } \\
\text { code }\end{array}$ & $\begin{array}{c}\mathrm{AV}, \\
\mathrm{mg} \mathrm{KOH} / \mathrm{g}\end{array}$ & $\begin{array}{c}\mathrm{HV}, \\
\mathrm{mg} \mathrm{KOH} / g\end{array}$ & $\begin{array}{c}\text { lodine } \\
\text { value }\end{array}$ & Color \\
\hline AR1 & 7.8 & 43 & 68.2 & $\begin{array}{c}\text { Pale } \\
\text { yellow }\end{array}$ \\
\hline AR2 & 8.4 & 47 & 63.4 & $\begin{array}{c}\text { Light } \\
\text { brown }\end{array}$ \\
\hline
\end{tabular}

There are no differences concerning the $\mathrm{AV}$, $\mathrm{HV}$ and iodine value determined for AR1 and AR2 because tetra-functional molecules (G-TMP and GTME) of similar structure were used for the ARs synthesis. The lower value of AV observed for AR1 show the higher conversion degree of carboxyl to ester groups. According to the structural analysis, NMR and HV, it can be supposed that G-TME and G-TMP have four primary hydroxyl groups which was adequately used for calculation of reaction mixture for AR synthesis at 1.05 molar ratio of hydroxyl to carboxyl group.

\subsection{Rheological characteristic of ARs}

The rheological tests were carried out in the frequency range from 0.1 to $100 \mathrm{rad} / \mathrm{s}$ and deformation value of $5.0 \%$. The dependences of viscosity, storage modulus $\left(G^{\prime}\right)$ and loss modulus $\left(G^{\prime \prime}\right)$, which reflect elastic and viscous behavior, 
respectively, and mechanical loss factor $(\tan \delta)$ of pure ARs are given in Figures 3, 4 and 5.

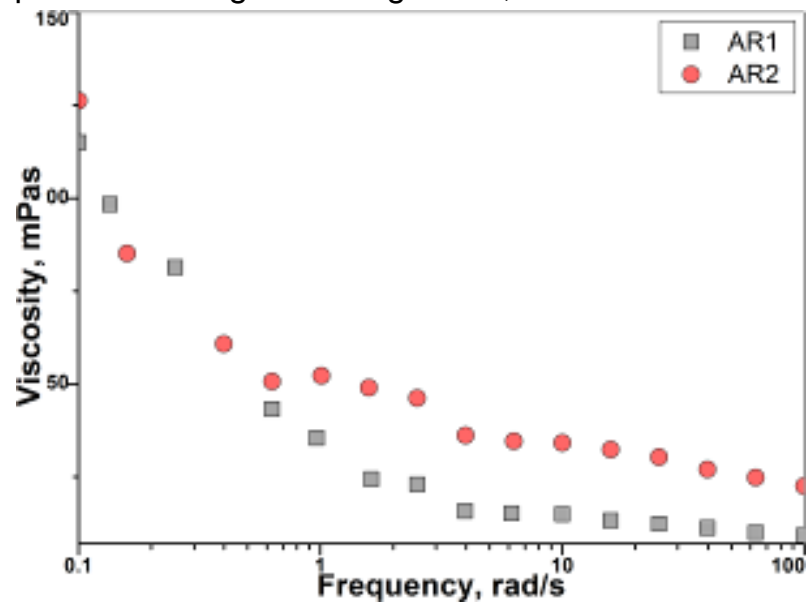

Figure 3 - The dependance of ARs viscosity on frequency
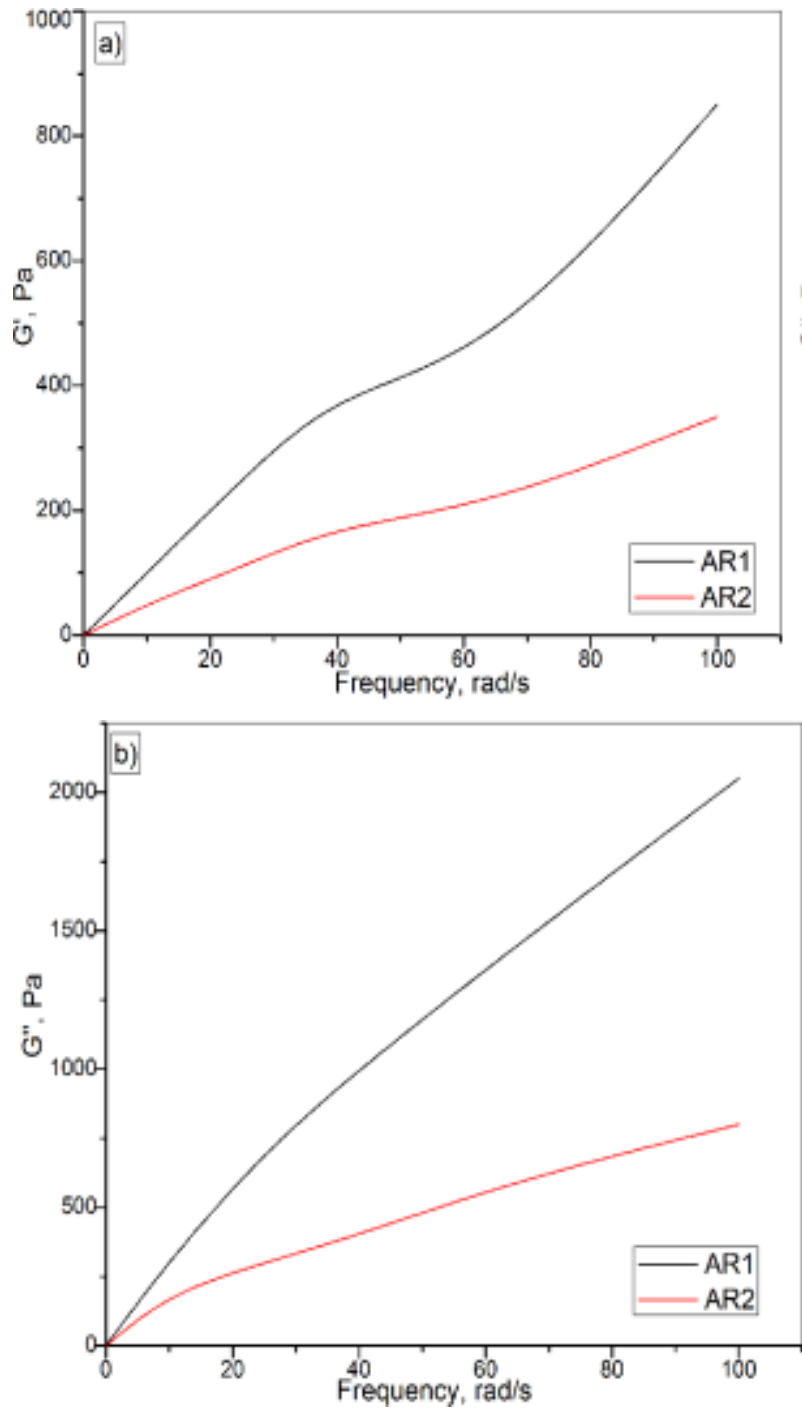

Figure 4 - The dependence of a) storage modulus $\left(G^{\prime}\right)$ and $\left.b\right)$ loss modulus ( $G$ ") of pure ARs on frequency
A slightly lower viscosity is observed in the low frequency region $(0.1-0.4 \mathrm{rad} / \mathrm{s})$ for AR2 comparing to AR1, after which viscosity decreases, while in the frequency region under $0.4 \mathrm{rad} / \mathrm{s}$, the higher viscosity is observed for AR2.

From the Figure 4, it can be seen that the pure AR1 has significantly higher $G$ ' and $G$ " values than pure AR2 in the whole investigated frequency region which indicates differences in cross-linking density of ARs. The values of $G^{\prime \prime}$ are higher comparing with $G$ ' values for both AR1 and AR2 resins.

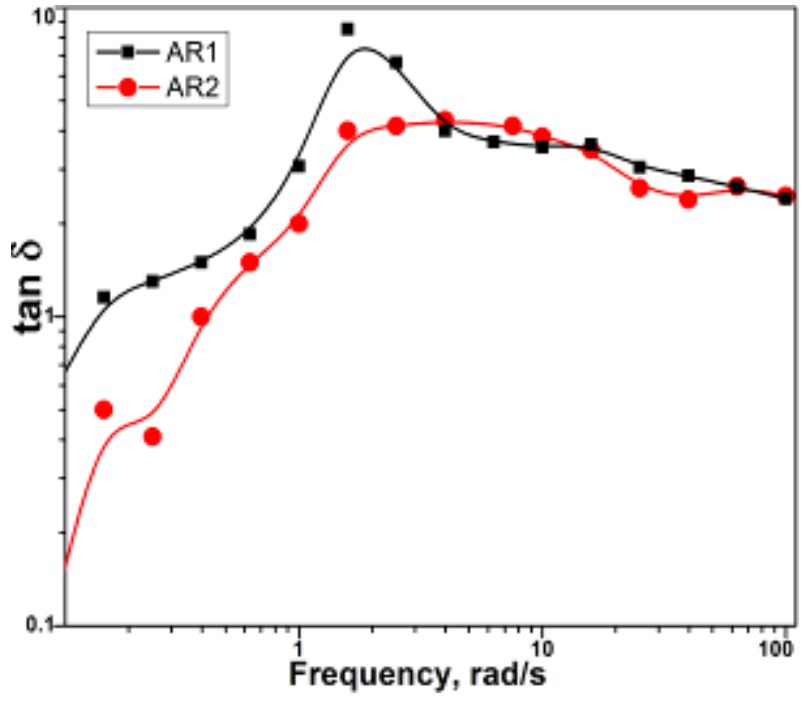

Figure 5 - The dependence of loss factor $(\tan \delta)$ of pure ARs versus frequency

The $\tan \delta$ height for AR1 is higher (8.5) than $\tan \delta$ height of AR2 (4.0) which indicated that there is restricted molecular mobility of AR2 polymer chains. Also, from the Figure 5, it can be observed that $\tan \delta$ peak is broader in case of AR2 than of AR1.

3.5. Mechanical testing of ARs and nanocomposite films

All coatings showed no cracking when subjected to the cupping tester (Table 3 ). This result indicated that the cross-linked films, for the obtained thickness of analyzed coating, were relatively flexible and adherent to substrate.

Table 3 - The gloss, hardness, thickness and adhesion properties of the prepared ARs films

\begin{tabular}{|c|c|c|c|c|}
\hline $\begin{array}{c}\text { Alkyd } \\
\text { code }\end{array}$ & $\begin{array}{c}\text { Gloss, } \\
60^{\circ}, \%\end{array}$ & Hardness & $\begin{array}{c}\text { Thickness } \\
\mu m\end{array}$ & Adhesion \\
\hline AR1 & 96.3 & 55.8 & 60.1 & 0.4 \\
\hline AR2 & 95.1 & 62.8 & 65.9 & 0.5 \\
\hline
\end{tabular}


It can be seen from Table 3 that the gloss at $60^{\circ}$ is excellent for both ARs which confirms homogeneous drying/cross-linking throughout the thickness of the film and good compatibility of the reactants (G-TMP and G-TME with FAL and PA), which caused good film-forming and leveling properties.

The crosshatch adhesion method was used for the determination of the adhesion of ARs films. A rating system of 0 to 5 was used to convey the degree of adhesion loss in which 0 indicates no coating removal, while 5 indicates the removal of more than 65 percent of the coating from the test area. The reproducible adhesion test results showed that both synthesized ARs had high adhesion (Table 3 ) because of high number of terminal hydroxyl groups, which could interact with the metal surface and homogeneous drying/crosslinking by auto-oxidation throughout the thickness of the film.

In Table 4, the test results of thickness and mechanical properties of nanocomposite films based on ARs and modified silica nanoparticles are shown.

Table 4 - The results of hardness, thickness and adhesion testing of nanocomposite coating

\begin{tabular}{|c|c|c|c|c|}
\hline Alkyd code & Hardness & Thickness, $\mu m$ & Adhesion & Dry-to-touch time, $h$ \\
\hline $\mathrm{AR} 1 / \mathrm{SiO}_{2} \mathrm{MA}$ & 67.0 & 61.5 & 0 & 6.0 \\
$\mathrm{AR} 1 / \mathrm{SiO}_{2} \mathrm{VY}$ & 72.5 & 63.8 & 0 & 6.0 \\
$\mathrm{AR} 2 / \mathrm{SiO}_{2} \mathrm{MA}$ & 75.7 & 67.2 & 0 & 6.0 \\
$\mathrm{AR} 2 / \mathrm{SiO}_{2} \mathrm{VY}$ & 78.0 & 68.0 & 0 & 7.0 \\
\hline
\end{tabular}

From the result presented in Table 4, it can be seen that there is a considerably influence of modified silica nanoparticles on mechanical properties of ARs nanocomposite. All of samples had excellent adhesion (Figure 6 ) and hardness in comparison to pure ARs.

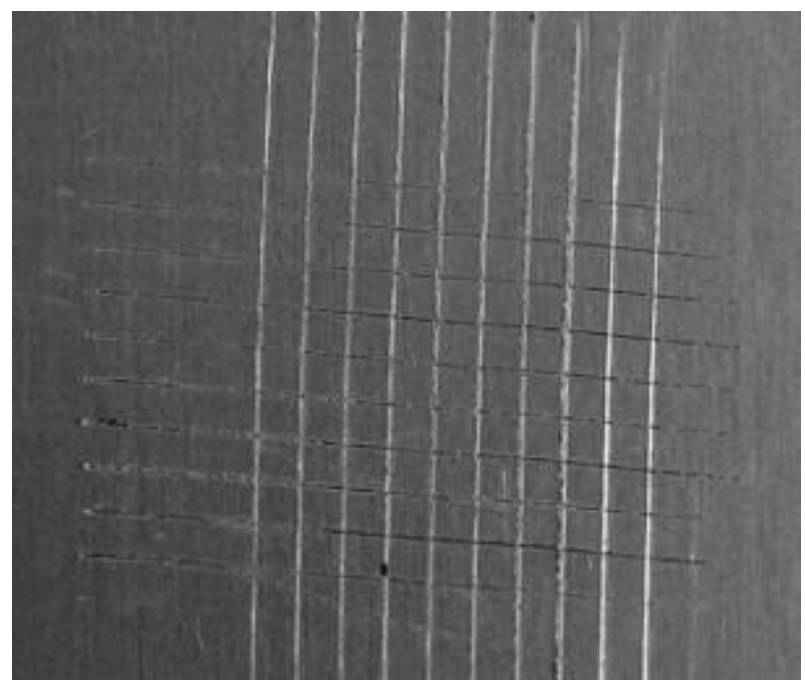

Figure 6 - Dry $\mathrm{AR} 1 / \mathrm{SiO}_{2} \mathrm{MA}$ coating film after crosshatch adhesion testing

The thickness of ARs nanocomposite is higher than thickness of pure ARs films indicating that there are interactions between nanoparticles and polymer matrix. Dry films of the nanocomposite films based on ARs and modified silica nanoparticles on metal and glass plate are shown in Figure 7a) and 7b), respectively. It can be seen that the samples have satisfying transparency so they can be used as lacquers and stains.
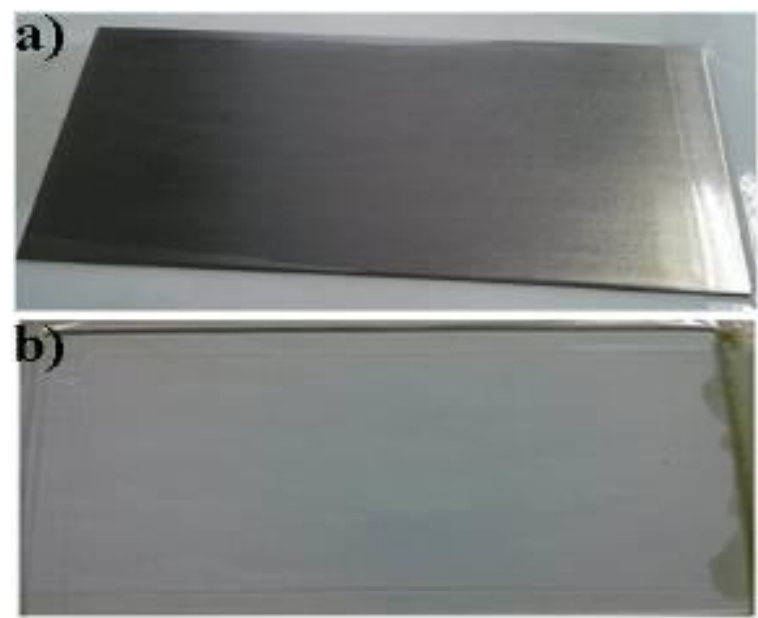

Figure 7 - Alkyd resin based on G-TMP and $\mathrm{SiO}_{2} \mathrm{MA}$ on metal a) and glass plate b)

3.6. Anticorrosion properties of the obtained dry $A R$ coating films

Investigated alkyd anticorrosion coatings (Figure 8) were composed of synthesized ARs (30 wt.\%), zinc phosphate (20 wt.\%) and the filler. Zinc phosphate and appropriate fillers were mixed with ARs in the per-mill. The appearance of dry ARs anticorrosion nanocomposite coating films based on AR1/SiO $2 \mathrm{MA}, \mathrm{AR} 1 / \mathrm{SiO}_{2} \mathrm{VY}, \mathrm{AR} 2 / \mathrm{SiO}_{2} \mathrm{MA}$ and $\mathrm{AR} 2 / \mathrm{SiO}_{2} \mathrm{VY}$, designated Co-AR1/SiO $2 \mathrm{MA}$, CoAR1/SiO 2 VY, Co-AR2/SiO ${ }_{2} \mathrm{MA}$ and Co$\mathrm{AR} 2 / \mathrm{SiO}_{2} \mathrm{VY}$ after anticorrosion analysis is shown on Figure 8.

Thickness, adhesion test results, swelling, corrosion, spraying and layering of untreated plate in humid and salt chambers are shown in Tables 5 and 6 , respectively. 
Table 5 - Thickness, adhesion, swelling, corrosion and spraying of nanocomposites coating in humid chamber

\begin{tabular}{|c|c|c|c|c|c|}
\hline Coating film & Thickness, $\mu m$ & Adhesion* & Swelling* & Corrosion & Spraying* \\
\hline Co-AR1/SiO $2 \mathrm{MA}$ & 100 & 0 & 0 & Ri0 & 0 \\
\hline Co-AR1/SiO ${ }_{2}$ VY & 109 & 0 & 0 & Rio & 0 \\
\hline Co-AR2/SiO ${ }_{2} \mathrm{MA}$ & 115 & 0 & 0 & RiO & 0 \\
\hline Co-AR2/SiO ${ }_{2}$ VY & 121 & 5 & 0 & RiO & 0 \\
\hline
\end{tabular}

*0-excellent; 5-bad;

Table 6 - Thickness, adhesion, swelling, corrosion and spraying of nanocomposites coating in salt chamber

\begin{tabular}{|c|c|c|c|c|c|}
\hline Coating film & Thickness, $\mu m$ & Adhesion* & Swelling* & Corrosion & Spraying* \\
\hline Co-AR1/SiO $2 \mathrm{MA}$ & 103 & 0 & 0 & Ri0 & 0 \\
\hline Co-AR1/SiO ${ }_{2}$ VY & 108 & 0 & 0 & Rio & 0 \\
\hline Co-AR2/SiO ${ }_{2} \mathrm{MA}$ & 119 & 0 & 0 & Ri0 & 0 \\
\hline Co-AR2/SiO ${ }_{2} \mathrm{VY}$ & 122 & 5 & 0 & Ri0 & 0 \\
\hline
\end{tabular}

${ }^{*}$-excellent; 5-bad

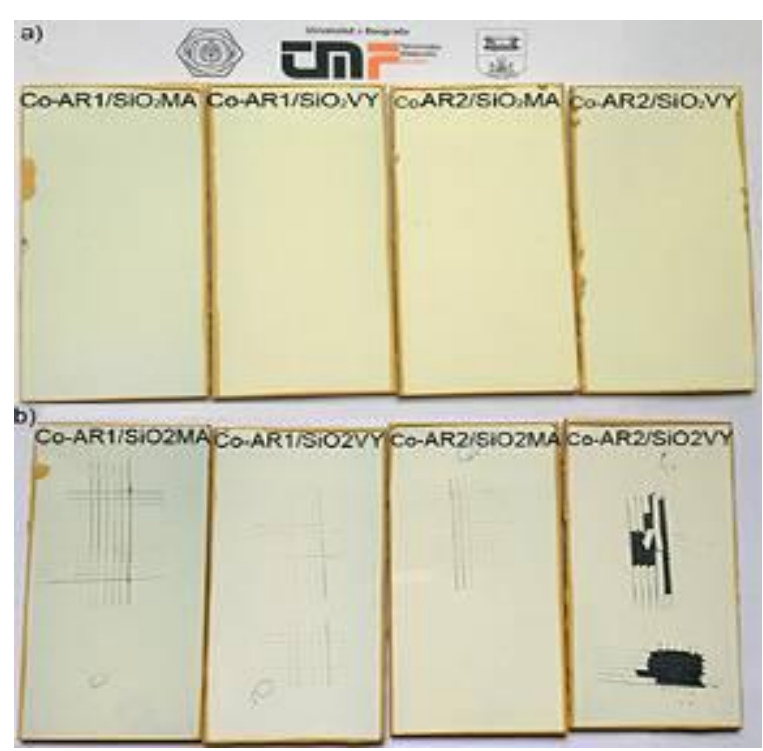

Figure 8 - Dry ARs anticorrosion coating films: Co$A R 1 / \mathrm{SiO}_{2} \mathrm{MA}$, Co-AR1/SiO $\mathrm{VY}$, Co-AR2/SiO $\mathrm{MA}$ and $\mathrm{Co}-\mathrm{AR2} / \mathrm{SiO}_{2} V Y$ a) before and $b$ ) after anticorrosion analysis in humid chamber

The results of thickness of dry anticorrosive films are in the range from 100 to $122 \mu \mathrm{m}$. Comparing to the anticorrosion test results of untreated ARs coating films in humid and salt chamber, it can be concluded that obtained nanocomposite coating films (except Co-AR2/SiO ${ }_{2} \mathrm{VY}$ in humid and salt chamber) satisfy the requirements of the prescribed quality standards.

\section{CONCLUSION}

The main purpose of this work was to investigate the possibility of waste-PET glycolizate application for alkyd resin production. Therefore, waste PET-based alkyd resins were prepared by reaction of the glycolysis products, G-TMP and GTME, with penthaerythritol, trimethylolpropane, phthalic anhydride and linseed oil fatty acids. In order to evaluate the obtained glycolysis products and alkyd resins, their thorough characterization was performed. The rheological study showed that pure alkyd resin, AR1 possesses significantly higher $G^{\prime}$ and $G^{\prime \prime}$ values compared to pure AR2, leading to conclusion that there are some differences in cross-linking density of ARs. All synthesized ARs show good adhesion and hardness.

Nanocomposites obtained from alkyd resins (AR1 and AR2) and vinyl and methacryloyl modified silica particles $\left(\mathrm{SiO}_{2} \mathrm{VY}\right.$ and $\left.\mathrm{SiO}_{2} \mathrm{MA}\right)$, were prepared with the aim to study the influence of silica modification on mechanical and anticorrosive properties of the obtained coatings. The results of the mechanical properties of the obtained coatings showed that improved mechanical properties were found for nanocomposite coatings comparing to coatings obtained from pure alkyd resins. The anticorrosive testing results pointed out that studied anticorrosive coatings satisfied the quality standards, except for the adhesion test failure obtained in the case of $\mathrm{Co}-\mathrm{AR} 2 / \mathrm{SiO}_{2} \mathrm{VY}$ nanocomposite coating in both humid and salt chamber.

\section{Acknowledgements}

The authors acknowledge financial support from Ministry of Education, Science and Technological development of Serbia, Project No. Ol 172057.

\section{REFERENCES}

[1] P.G.Karayannidis, S.D.Achilias, D.I.Sideridou, N.D.Bikiaris (2005) Alkyd resins derived from glycolized waste poly(ethylene terephthalate), European Polymer Journal, 41, 201-210.

[2] G. Güçlü, M.Orbay (2009) Alkyd resins synthesized from postconsumer PET bottles, Progress in Organic Coatings, 65, 362-365. 
[3] A.Torlakoğlu, G.Güçlü (2009) Alkyd-amino resins based on waste PET for coating applications, Waste Management, 29 (1), 350-354.

[4] J.Rusmirović, T.Radoman, E.Džunuzović, J. Džunuzović, J.Markovski, P.Spasojević, A Marinković (2015) Effect of the modified silica nanofiller on the mechanical properties of unsaturated polyester resins based on recycled polyethylene terephthalate, Polymer Composites, in press.

[5] J.Dullius, C.Ruecker, V.Oliveira, R.Ligabue, S.Einloft (2006) Chemical recycling of postconsumer PET: Alkyd resins synthesis. Progress in Organic Coatings, 57, 123-127.

[6] P.Spasojević, V.Panić, J.Džunuzović, A.Marinković, A.Woortman, K.Loosd, I.Popović (2015) High performance alkyd resins synthesized from postconsumer PET bottles, RSC Advances, 5, 62273-62283.

[7] M.Soucek, M.K.G.Johansson (2012) Alkyds for the 21st century, Progress in Organic Coatings, 73 (4), 273.

[8] A.Hofland (2012) Alkyd resins: From down and out to alive and kicking, Progress in Organic Coatings, 73 (4), 274-282.

[9] S.Kangoa, S.Kalia, A.Celli, J.Njuguna, Y.Habibi, R.Kumar (2013) Surface modification of inorganic nanoparticles for development of organic-inorganic nanocomposites-A review, Progress in Polymer Science, 38, 1232-1261.

[10] M.Castellano, A.Turturro, E.Marsano, L.Conzatti, S.Vicini (2014) Hydrophobation of silica surface by silylation with new organo-silanes bearing a polybutadiene oligomer tail, Polymer Composites, 35, $1603-1613$.

[11] L.Guo, X.Xu, Y.Zhang, Z.Zhang (2014) Effect of functionalized nanosilica on properties of polyoxymethylene-matrix nanocomposites, Polymer Composites, 35, 127-136.

[12] L.Tong, Z.Pu, Z.Chen, X.Huang, X.Liu (2014) Effect of nanosilica on the thermal, mechanical, and dielectric properties of polyarylene ether nitriles terminated with phthalonitrile, Polymer Composites, 35, $344-350$.

[13] Y.Li, C.Han, X.Zhang, J.Bian, L.Han (2013) Rheology, Mechanical Properties, and Biodegradation of Poly(e-caprolactone)/Silica Nanocomposites, Polymer Composites, 34, 1620 1628.

[14] M.Castellano, A.Turturro, E.Marsano, L.Conzatti, S.Vicini (2014) Hydrophobation of silica surface by silylation with new organo-silanes bearing a polybutadiene oligomer tail, Polymer Composites, 35, 1603 - 1613.

[15] R.Hong, H.Fu, Y.Zhang, L.Liu, J.Wang, H.Li, Y.Zheng (2007) Surface-modified silica nanoparticles for reinforcement of PMMA, Journal of Applied Polymer Science, 105, 2176-2184.

[16] I.Popović, J.Rusmirović, M.Rančić, A.Tasić, D.Lazić, A.Marinković (2015) Synthesis of highperformance alkyd anticorrosion coatings based on waste poly(ethylene terephthalate), Zaštita Materijala, 56(4), 482-493.

[17] ISO 4326:1992: Non-ionic surface active agents Polyethoxylated derivatives -Determination of hydroxyl value - Acetic anhydride method.

[18] ASTM D3644: Standard Test Method for Acid Number of Styrene-Maleic Anhydride Resins, 2012.

[19] ISO 1520, Paints and varnishes -Cupping test, 2006.

[20] ASTM D 3359, Standard Test Methods for Measuring Adhesion by Tape Test, 2002.

[21] ASTM D 523, Standard Test Method for Specular Gloss, 2014.

[22] ASTM D 4366, Standard Test Methods for Hardness of Organic Coatings by Pendulum Damping Tests, 2014.

[23] SRPS EN ISO 4628,Paints and varnishes Evaluation of degradation of coatings - Designation of quantity and size of defects, and of intensity of uniform changes in appearance, 1998.

\section{IZVOD}

\section{ALKID NANOKOMPOZITNI PREMAZI BAZIRANI NA OTPADNIM PET GLIKOLIZATIMA MODIFIKOVANI NANOČESTICAMA SILIKE}

$U$ ovom radu prikazana je sinteza alkidnih smola visokih performansi baziranih na otpadnim poli(etilentereftalat) (PET) glikolizatima. PET glikolizati su sintetisani katalitičkom depolimerizacijom sa trimetilolpropanom (TMP) i trimetiloletanom (TME) koji su korišćeni za zamenu polihidroksilne komponente $u$ toku sinteze alkidnih smola. Dobijeni glikolizati $i$ alkidne smole $u$ velikom prinosu su okarakterisane FTIR $i{ }^{1}$ HNMR spektroskopijom, kiselinskim, jodnim $i$ hidroksilnim brojem. Određena su reološka svojstva sintetisanih alkidnih smola kao što su debljina, athezija, tvrdoća i sjaj i sve sintetisane alkidne smole su pokazale veliku adeziju i tvrdoću i sjaj veći od $98 \%$. Ispitivan je uticaj dodatka modifikovanih silika Aerosil ${ }^{\circledR} R 380$ nanočestica na mehaničke I antikorozivne karakteristike dobijenih nanokompozitnih premaza na bazi alkidnih smola.

Ključne reči: Alkidne smole, otpadni PET glikolizati, nanosilika, nanokompozitni premazi.

Naučni rad

Rad primljen: 15.10 .2015$.

Rad prihvaćen: 09.12.2015.

Rad je dostupan na sajtu: www.idk.org.rs/casopis 